\title{
Entre os auditórios, clínicas, engenhos e os cárceres do Santo Ofício: cristãos-novos letrados no Rio de Janeiro (séculos XVII e XVIII)
}

\author{
CARLOS EDUARDO CALAÇA*
}

\begin{abstract}
Resumo: O objetivo desse artigo é conhecer a História dos cristãos-novos, nascidos ou residentes no Rio de Janeiro que freqüentaram a Universidade de Coimbra, entre os anos de 1650 e 1730. As principais fontes documentais utilizadas são seus processos, quando presos pelo Tribunal do Santo Ofício da Inquisição de Lisboa. Entramos em contato com depoimentos que revelam ambientes pelos quais passaram, dentre os quais a Universidade de Coimbra e o Rio de Janeiro, em seus sistemas de lealdade, crenças e costumes.

Abstract: The purpose of this article is to know the History of the New Christians who were born or lived in Rio de Janeiro and who have studied at the University of Coimbra between 1650 and 1730. The main sources of documents used are their processes when they were arrested by the Trial of Inquisition of the Holy Office in Lisbon. We have found depositions that reveal where they've been to, such as the University, with it system of loyalty, beliefs and habits.
\end{abstract}

Palavras-chave: Cristãos-novos. Universidade de Coimbra. Inquisição.

Key words: New Christians. University of Coimbra. Inquisition.

Alguns cristãos-novos do Rio de Janeiro, antes de iniciarem suas viagens de estudo, eram advertidos por seus pais ou parentes mais velhos sobre os cuidados que deveriam tomar nas margens do Rio Mondego. O histórico dos motins contra os estudantes de

\footnotetext{
Doutor em História Social na Faculdade de Filosofia, Ciências Humanas e Letras USP. Pesquisador do Laboratório de Estudos sobre Intolerância/FFLCH-USP e Pesquisador do Departamento de História Pró-Reitoria de Pós-Graduação e Pesquisa da Universidade Salgado de Oliveira - Niterói/RJ.
}

Estudos Ibero-Americanos. PUCRS, v. XXXI, n. 2, p. 207-219, dezembro 2005 
origem judaica (1605 e 1630) ${ }^{1}$ e a existência de um Tribunal do Santo Ofício às portas da Almedina exigiam que os fluminenses se acautelassem durante suas estadas na Universidade de Coimbra. Era costume dos ascendentes ou ex-penitenciados mais velhos, residentes no Rio de Janeiro, prevenirem os futuros estudantes sobre os procedimentos a serem tomados, no caso de serem presos pela Inquisição.

Saber como proceder diante do Tribunal significava salvaguardar a vida e evitar que permanecessem por longo período nos cárceres inquisitoriais; para tanto, tornava-se importante que as confissões fossem planejadas: aos cristãos-novos, ensinavam-se as práticas e as atitudes adequadas diante dos Inquisidores, ou seja, as etapas do processo, o que confessar, a quem denunciar ou não, para que pudessem salvaguardar suas vidas e a de seus familiares. ${ }^{2}$ Tratava-se de um dos principais escopos da educação dos cristãos-novos: uma educação de técnicas confessionais para assegurar a sobrevivência.

\section{A educação para a confissão: as fórmulas planejadas}

Em algumas famílias cristãs-novas, uma das mais importantes orientações que o jovem calouro recebia de seus progenitores, antes de embarcar para a viagem de estudo, era a respeito do procedimento a ser tomado caso preso pelo Tribunal do Santo Ofício. Tratava-se do ensino do que confessar para assegurar sua defesa e sobrevivência. Independentemente de sua educação formal, cujos fundamentos teriam outras finalidades, era necessária a inculcação de uma educação de como proceder, caso se vissem encarcerados no Santo Ofício, principalmente às vésperas de partirem para o Reino, onde estariam diante do Tribunal de Coimbra.

Muitos, de fato, sabiam exatamente como proceder diante do Santo Ofício quando presos pelo Tribunal em princípios do século XVIII, época em que grande parte já havia retornado da Universidade e que a Inquisição atuava com veemência no Rio de Janeiro. Confessavam suas "culpas" seguindo determinadas fórmulas padronizadas e difundidas no mundo ibérico. Tratar-se-ia de uma importante fase na vida do futuro estudante (e, possivelmente de

1 Cf. OLIVEIRA, Antônio de. O motim dos estudantes de Coimbra contra os cristãosnovos em 1630. Biblos, Coimbra, n. 57, 1981 (separata).

2 Sobre o tema, cf. NOVINSKY, Anita. Confessa ou Morre. Sigila: reoue transdiciplinaire franco-portuguaise sur le secret, n. 5 - Confessions. Paris: Primavera-verão, 2000, p. 77105. 
todos os cristãos-novos, potenciais alvos dos Tribunais do Santo Ofício portugueses), quando recebia a educação para a sobrevivência. Afinal, como bem notou Anita Novinsky, ou confessava, ou morria. ${ }^{3} \mathrm{E}$, além disso, era necessário que confessasse o certo para que suas estadas nos cárceres fossem breves.

Ao formalismo do Santo Ofício, o réu deveria responder com as mesmas letras, ou seja, incorporando o seu depoimento nas normas inquisitoriais, possivelmente procurando resolver exemplarmente o seu problema: o de estar preso e o de querer se livrar o mais breve possível dos cárceres inquisitoriais.

O médico Diogo Cardoso Coutinho, preso no dia 10 de outubro de 1712, solicita, dois dias após a sua entrega ao Alcaide dos Cárceres, uma audiência com o inquisidor e inicia sua confissão. ${ }^{4}$ Tratou de delatar a mãe, seis irmãos e uma tia. Sabia que haviam sido presos e não se preocupou em ocultar o fato. ${ }^{5}$ Logo a seguir, denunciou outros parentes que já haviam passado pelos cárceres e já estavam reconciliados pelo Santo Ofício. Por fim, em suas confissões proferidas em 12 de outubro, 23 de novembro e 10 de dezembro de 1712, denunciou uma série de pessoas, "conjuntas e não conjuntas", com as quais havia compartilhado a crença na Lei de Moisés e que sabia terem sido presas ou já penitenciadas pelo Santo Ofício. ${ }^{6} \mathrm{Na}$ sessão de genealogia, de 15 de dezembro de 1712 , declara que sabia dos parentes presos e enumera um a um. ${ }^{7}$

O estudante de Leis, Antônio Coelho, passado pouco mais de um mês da confissão que havia feito no Tribunal de Lisboa, quando apresentado, decidiu-se novamente comparecer aos estaus, só que desta feita ao Tribunal de Coimbra. Segundo ele, movido pelos conselhos que lhe dera o Padre Frei Francisco de Anunciação, com quem havia se confessado pouco tempo antes, decidira contar a "verdade", desmentindo a versão que dera à Inquisição de Lisboa,

onde confessou ter vivido na Lei de Moisés pelo ensino que da mesma lhe tinha feito Dioguinho, caixeiro de José Gomes, porquanto com o dito Dioguinho não passou coisa alguma, falsamente disse dele, por the haver dito seu tio Manoel de Paredes que se fosse em algum tempo preso pelo Santo Ofício, não desse por autor do seu ensino a sua mãe, ainda que defunta por que dizendo dela necessariamente teria também de dizer de suas

3 Ibid.

4 Cf. Instituto Arquivo Nacional/Torre do Tombo, Inquisição de Lisboa, Processo de Diogo Cardoso Coutinho, n. 10.168.

Ibid.

Ibid.

Ibid. 
irmãs, os queria reservar pelo amor que lhes tinha de na Inquisição de Lisboa por autor a Dioguinho, dizendo que este o mandara ter com André de Barros, o que tal não foi... [grifos nossos]. ${ }^{8}$

Possivelmente, o "ensino" que lhe dera o falecido senhor de engenho, marido de sua prima Catarina Marques, fora recorrente, quando, em princípios do XVIII, a Inquisição atuava no Rio de Janeiro. Antônio Coelho sabia que poderia acabar preso caso seguisse o ingênuo aconselhamento deixado pelo tio e não denunciasse sua família e outros integrantes da comunidade que já haviam sido encarcerados. Nesta sessão, relata ter se declarado como crente e observante da Lei de Moisés com quase todos os seus irmãos e irmãs, além de também denunciar sua avó por via materna, Dona Ignês Aires, cristã-nova, natural do Reino, residente no Rio de Janeiro, depois presa pelo Santo Ofício. ${ }^{9}$

Por sua vez, o estudante de gramática Guilherme Gomes Mourão, preso em 10 de outubro 1712, denunciou seus parentes (primeiros e segundos) e, mesmo assim, o Promotor Fiscal do Santo Ofício insistiu para que se publicasse o seu libelo em 23 de fevereiro de 1713 (talvez para alongar um pouco mais o processo, que corria excessivamente rápido, e extrair do réu maior número de confrades da suposta crença mosaica). Apesar de ter solicitado a presença de um procurador para elaborar sua defesa, Guilherme alegou apenas que não se lembrava dos ocultos delatores apresentados na sessão In Spécie, "mas que ao se lembrar, iria à mesa confessar". De fato, um mês depois, solicitou audiência ao inquisidor Francisco Carneiro de Figueiroa e deu continuidade às suas confissões, denunciando principalmente os que já haviam sido presos pelo Santo Ofício. ${ }^{10}$

Antônio José Saraiva diria que "tanta fartura é suspeita", ${ }^{11} \mathrm{e}$ nós completaríamos afirmando que tanto formalismo também o é. Caso a cartilha fosse seguida à risca, com alguns depoimentos que lhe conferissem certo grau de legitimidade, compondo o quadro de denúncias das cerimônias associadas ao judaísmo difundidas no mundo ibérico, o réu dava um passo para que não permanecesse por muito tempo nos cárceres; o importante é que dissesse de si "bastantemente, de seus pais, irmãos, primos e muitas mais pessoas conjuntas e não conjuntas, com muitas das quais não estava indiciado, satisfazendo toda a prova de justiça porque foi preso e

Cf. IAN/TT, Inquisição de Lisboa, processo de Antônio Coelho de Oliveira, n. 9.319. Ibid.

10 Cf. IAN/TT, Inquisição de Lisboa, Processo de Guilherme Gomes Mourão, n. 947.

11 Cf. SARAIVA, Antônio José. Inquisição e Cristãos-novos. Lisboa: Estampa, 1985. 
acusado". Estaria pronto para ser penitenciado e recebido "ao Grêmio e União da Santa Madre Igreja".

As "vozes" que nos chegam através da documentação inquisitorial nos informam o empenho de alguns, ao iniciarem confissões, em produzirem uma retórica diante dos funcionários do Santo Ofício. A maior parte desses letrados, formada em Direito Canônico, em vez de elaborar complexas discussões teológicas - como o fez o tão famoso Henequim -, criou métodos práticos para solucionar seus problemas. Buscavam, assim, dar continuidade às suas vidas e reaver suas liberdades, mesmo que empobrecidos.

\section{A educação para "os bons costumes"}

Uma das grandes tarefas da Universidade era a formação estudantil com os padrões das "boas maneiras" e das "reverências", ao estilo de uma instituição barroca de Antigo Regime. A função era a de formar quadros que futuramente representassem os interesses dos universitários e de setores vinculados à Monarquia Católica. Os cristãos-novos fluminenses assistiam, quase que diariamente, aos procedimentos ritualísticos litúrgicos ou seculares; procissões e préstitos eram parte representativa do calendário acadêmico, além dos autos-de-fé que, vez por outra, desfilavam pela praça do comércio, às portas da subida da Almedina.

Da abertura ao término do ano letivo, o corpo universitário era obrigado a participar de uma série de rituais de cariz religioso. ${ }^{12} \mathrm{O}$ cristão-novo Antônio Nunes Ribeiro Sanches, ao passar pela Universidade, não deixou de registrar o calendário litúrgico,

12 "Estudantes e professores partilhavam de um quotidiano expressamente tutelado por santos, protetores e bem-aventurados e subordinavam os principais atos de sua vida acadêmica a um autêntico compromisso religioso. Estatutariamente, todos os exames e atos de grau, desde o primeiro ano até ao de conclusões magnas para doutoramento, eram antecedidos por uma oração latina, recitada pelo candidato, que continha uma invocação à Santíssima Trindade e à Imaculada Conceição. Os estudantes eram obrigados a juramento religioso no ato da matrícula, os professores faziam-no no início do ano letivo, era o chamado juramento dos lentes, o grau de licenciado era atribuído na capela, o de doutoramento iniciava-se com missa. E esses eram, entre outros, dias especiais na Universidade, qualquer que fosse o grau de fidelidade a estas praxes". Cf. ARAÚJO, Ana Cristina Bartolomeu. As horas e os dias da Universidade. In: Universidade(s): História, Memória, Perspectivas. Coimbra: Comissão Organizadora do Congresso 'História da Universidade, 1991, Acta III, p. 365-382, aqui p. 371. 
observando que dos 7 meses do ano letivo apenas 3 eram de aulas, sendo o restante composto por cerimoniais religiosos. ${ }^{13}$

A disciplina pela via coercitiva também ocorre com certa freqüência na Universidade. ${ }^{14} \mathrm{~A}$ instituição contava com a sua cadeia privativa e o seu próprio oficial, o Carcereiro, um vigilante direto sobre o comportamento dos estudantes e que, por isso, perante eles, era dotado de grande poder simbólico. ${ }^{15}$

A passagem dos cristãos-novos fluminenses pela Universidade de Coimbra, entre 1650 e 1730, foi discreta. Ouviram os conselhos dos que os preveniram. Pessoas em geral que diziam ser "de mui juízo e capacidade" e que os encaminhavam "no que mais lhe(s) convinha". ${ }^{16}$ Procuraram se agregar ao corpo religioso da Universidade, seguir os preceitos sacramentais, litúrgicos etc. Há casos de cristãos-novos que receberam o crisma enquanto estudantes em Coimbra e outros pertenceram às irmandades religiosas. ${ }^{17}$

No total, registrei 37 estudantes cristãos-novos, fluminenses, que durante certo período de suas vidas freqüentaram a Universidade de Coimbra. A maioria se matriculou na Faculdade de Sagrados Cânones, seguindo uma tendência mais geral dos estudantes conimbricenses de todo o Império. Dos 37, 18 estudaram Cânones; 10, medicina; 6, leis e 3, Instituta. O predomínio do Direito Canônico pode ser associado a uma tendência mais geral dos alunos portugueses e ultramarinos, tendo em vista a possibilidade de inserção em carreiras civis e eclesiásticas. No entanto, para os cristãos-novos, o Direito Canônico poderia servir como salvaguarda devido às suas origens judaicas e ao sistema persecutório ao qual estavam submetidos. Mesmo que não seguissem a carreira eclesiástica, a formação em Direito Canônico propiciava uma multiplicidade de argumentos e comportamentos sociais oportunos para

13 Cf. SANCHES, Antônio Nunes Ribeiro. Obras. Vol. 1. Método para aprender e estudar a medicina. Cartas sobre a educação e a mocidade. Coimbra: Universidade de Coimbra, 1959.

14 "Estatutos da Universidade de Coimbra (1653) por ordem Del Rey Dom João IV". In: Silva, José Justiniano de Andrade. Colecções Chronológica da Legislação Portuguesa, Lisboa, 1824, 10 vols, vol. VII, p. 129-292.

15 Cf. OLIVEIRA, Antônio de. A Universidade e os poderes. In: História da Universidade em Portugal. Coimbra-Lisboa: Universidade de Coimbra, Fundação Calouste Gulbenkian, vol. I, tomo II, 1997, p. 919-922.

16 Este jargão é recorrente nos processos examinados, quando o prisioneiro dizia ter recebido o seu primeiro ensino.

17 Como no caso de Francisco Gomes Deniz, estudante canonista, que serviu à irmandade de Nossa Senhora do Desterro na Igreja de São João da Universidade de Coimbra. Cf. IAN/TT, Inquisição de Lisboa, Processo de Francisco Gomes Diniz, no 11.001 . 
que cumprissem os "mandamentos" do mundo - termo freqüentemente utilizado por eles nos processos inquisitoriais.

Talvez a viagem de estudos e a formação em Cânones possam ser explicadas na tentativa de assimilação aos padrões do "bom comportamento", de "acortesamento" ou de "civilidade" nos modelos de uma ascendente nobreza de toga. ${ }^{18}$ No caso dos cristãos-novos, para além da inserção plena na boa sociedade, a disciplina do corpo e da mente, nos moldes católicos-cristãos, visava garantir também a negociação de sua estada neste universo que a qualquer momento lhes poderia tornar-se hostil.

Assim, os novos cristãos do Rio de Janeiro, principalmente na segunda metade do século XVII, arriscaram suas caríssimas viagens de estudos. Não sofreram maiores problemas com a Inquisição durante suas estadas na Universidade. Já os do século XVIII conviveram em um clima de insegurança e ansiedade mais acentuado ao tomarem conhecimento das prisões de parentes ocorridas no Rio de Janeiro e da possibilidade de serem delatados e presos. Lembremo-nos de que nas três primeiras décadas do século XVIII a cidade do Rio de Janeiro foi o principal alvo das ações inquisitoriais no ultramar, resultando num total de 345 presos, naturais ou moradores do Rio de Janeiro. ${ }^{19}$

Dos 37 casos estudados, 22 foram presos quando já haviam retornado ao Rio de Janeiro. Alguns exerciam profissões relacionadas às suas formações acadêmicas e outros se dedicaram a atividades diversificadas, associando muitas vezes o exercício de suas profissões com as plantações e o comércio. Dos demais, 9 já haviam falecido - apesar de denunciados; 3 não foram presos, apesar de denunciados; 3 se apresentaram ao Santo Ofício, e outros 2 foram presos quando já residiam em Lisboa - e cujos pais já haviam sido penitenciados, inclusive queimados (casos de Antônio José da Silva e João Tomás de Castro).

18 Cf. ELIAS, Norbert. O Processo Civilizador: uma história dos costumes. Rio de Janeiro: Jorge Zahar Editor, 1994, vol. I.

19 Cf. NOVINSKY, Anita. Inquisição: Prisioneiros do Brasil (séculos XVI-XIX). Rio de Janeiro: Expressão e Cultura, 2002, p. 28-31. Registre-se que o número de presos naturais do Rio de Janeiro é menor: homens: 146; mulheres: 141. 


\section{Ocupações}

A tendência mais geral por parte dos cristãos-novos fluminenses, assim como de outros estudantes ultramarinos, ${ }^{20}$ era a de retornar ao ponto de partida e apresentarem os seus anéis de doutos conimbricences no Rio de Janeiro. Ao retornarem, auxiliavam na "empresa familiar", núcleo importante dos negócios coloniais do litoral agro-exportador. Com o diploma, o antigo "filho de família", então doutor, licenciado ou bacharel, passava a representar os seus congêneres nos tribunais, na Igreja ou a assisti-los enquanto médicos, salvaguardando a saúde tanto da parentela e agregados quanto de suas propriedades humanas, os escravos. Evitavase, assim, o recrutamento de "estrangeiros" para assegurar propriedades e vidas e a própria honra da família, questões sagradas no seio da organização econômica, social e política da vida colonial.

Além disso, era conveniente que a família estabelecesse alianças políticas e matrimoniais com outros clãs da elite colonial. $\mathrm{O}$ exercício de atividades públicas e liberais reforçava as alianças com clãs não aparentados, através da ética do favor, do clientelismo ou mesmo da institucionalização de tais alianças através do casamento. Para os cristãos-novos, tais relações eram fundamentais.

Mesmo assim, as vias das letras por si só, no período retratado, não eram promissoras. No caso da colônia, a propriedade de engenhos e de escravos sobressaía. Alguns dos cristãos-novos, ao herdarem de seus pais os engenhos, abandonavam os seus ofícios forenses ou clínicos.

Alguns dos letrados exerceram temporariamente atividades relacionadas às suas formações, deslocando-se posteriormente para outras ocupações, principalmente para as da lavoura açucareira. Agostinho de Paredes, assim que retornou de Coimbra, iniciou sua carreira advogando na cidade do Rio de Janeiro e, depois de alguns anos nesse ofício, retirou-se para o Irajá, onde se dedicou ao seu engenho, comprado por volta de 1705. Para efetuar a compra, conseguiu, com a Fazenda de El Rei, a quem havia servido pouco antes como Procurador, ${ }^{21}$ um empréstimo de doze mil cruzados e trezentos mil réis. Na cidade, era dono de "umas casas

20 Cf. FONSECA, Fernando Taveira da. O saber Universitário e os universitários no ultramar. In: História da Universidade em Portugal. Coimbra-Lisboa: Universidade de Coimbra/Fundação Calouste Gulbenkian, v. 1, tomo 2, 1997, p. 1.032.

21 Segundo Agostinho, o engenho havia sido comprado do cristão-novo Pedro Mendes Henriques, no valor de 30.000 cruzados. O valor e a compra são confirmados no inventário de Pedro Mendes, também preso. Cf. Novinsky, Anita. Inquisição - Inventários de bens confiscados a cristãos-novos. Lisboa: Casa da Moeda/Liv. Camões, s.d., p. 25 e 227. 
térreas", as quais havia herdado de seu pai, avaliadas por ele em 2.000 cruzados. $^{22}$

Agostinho de Paredes deixou de lado a advocacia, embora tenha sido um dos advogados mais atuantes no Rio de Janeiro seiscentista e setecentista. ${ }^{23}$ Se a estima lhe era conferida pelo capital simbólico e pela competência no exercício de seu ofício, ao se tornar senhor de engenho no Irajá, nobilitara-se de fato. Em geral, é identificado pelos testemunhos como senhor de engenho; embora lhe coubesse o tratamento de "Doutor", nenhum dos depoentes interrogados em seu processo, nem mesmo o próprio Agostinho, menciona ter servido no lugar das letras quando Procurador da Coroa e da Fazenda Real, cargo que exerceu nos anos de 1683, 1687,1693 e $1697 .{ }^{24}$

Os cristãos-novos letrados, assim como grande parte dos colonos luso-brasileiros exerciam atividades diversificadas. ${ }^{25}$ Alguns deixavam seus partidos nas mãos de feitores e ficavam livres para o exercício de seus ofícios na cidade. O médico Teodoro Pereira da Costa, que tinha um partido de cana no engenho de Agostinho de Paredes, na época da colheita permanecia no campo; no entanto, residia na cidade, onde exercia o seu ofício, e deixava o partido nas mãos de "Domingos, homem preto, escravo dele [...] [e que] tratava do dito partido". ${ }^{26}$

Mesmo os que exerciam suas profissões não deixavam de se envolver em uma complexa rede de créditos e endividamentos que, muitas vezes, ultrapassava o espaço regional. Esse procedimento se iniciava já nas viagens de estudos. Os rapazes recebiam solicitações de fluminenses para o envio de mercadorias compradas em Lisboa a preços mais baixos para que fossem vendidas com lucro no mercado local. Teodoro Pereira da Costa recebia encomendas do Rio de Janeiro, uma das quais, inclusive, acabou em disputa forense com o advogado Miguel de Castro Lara. ${ }^{27}$

Ibid., p. 25.

3 Ibid.

24 Arquivo Nacional do Rio de Janeiro. Provisões da Fazenda Real do Rio de Janeiro. Igualmente é o caso de João Mendes da Silva, que, apesar de ter exercido o mesmo ofício, se intitula apenas como advogado.

25 Cf. SILVA, Lina Gorenstein F. da. Heréticos e impuros. A Inquisição e os cristãos-novos no Rio de Janeiro: século XVIII. Rio de Janeiro: Secretaria Municipal de Cultura, Departamento Geral de Documentação e Informação Cultural, Divisão de Editoração, 1995, p. 41; e Nazzari, Muriel. O Desaparecimento do dote: mulheres, famílias e mudança social em São Paulo, Brasil, 1600-1900. São Paulo: Companhia das Letras, 2001, p. 27-44.

26 Cf. IAN/TT, Inquisição de Lisboa, processo de Teodoro Pereira da Costa, n. 2222.

27 Ibid. 
Os acadêmicos também se envolveram em atividades mercantis com as minas. O advogado alentejano Damião Rodrigues Moeda, em sociedade com parentes (dentre os quais, o médico João Nunes Vizeu), envolveu-se em diversas carregações para as Minas de negros e vestimentas. Associavam-se para engrossar as carregações e auferir maiores lucros. ${ }^{28}$ Uma dessas carregações, no ano de 1706, transportava duas negras entregues a um mulato da confiança de Damião, e o mulato acabou por se apossar dos ganhos. Damião convocou um colega de ofício residente nas Minas, Francisco Amaral, para que cobrasse a importância em juízo. Vitorioso na causa, Francisco Amaral encarregou a dois sobrinhos as trezentas e oitenta e sete oitavas de ouro para serem entregues ao advogado alentejano radicado no Rio de Janeiro. Ambos foram seqüencialmente assassinados e a quantia, depositada no juízo dos defuntos e ausentes. Restou solicitar ao fluminense capitão Mateus de Moura Fogaça, a caminho das minas, a recuperação da quantia que, apesar de recobrada, não foi devolvida a Damião "sem embargo de as mandar pedir por várias vezes". ${ }^{29}$ Homem de negócio, envolvido em uma complexa rede de crédito e endividamento, Damião, no entanto, assim como outros letrados, paradoxalmente afirma em seu inventário "que não tinha contrato algum nesta corte porquanto vivia do seu ofício de advogado". 30

Inácio Cardoso de Azevedo, filho de Agostinho de Paredes (tio do advogado homônimo) e Ana de Azeredo, esteve também nas minas. ${ }^{31}$ Inácio, ao que parece, abandona a profissão e se associa ao irmão, Rodrigo Mendes de Paredes, nos negócios com as minas, no comércio de escravos, tecidos, cavalos, aguardente, sal, açúcar, queijos e, obviamente, minérios levados de uma região para a outra. ${ }^{32} \mathrm{O}$ advogado Sebastião de Lucena Montarroio também esteve nas minas. Comprou uma casa e, como Inácio, envolveu-se em transações comerciais diversificadas. Ao que parece, não abandonou o ofício, tanto assim que fez questão de transferir parte de sua livraria nas carregações que fez para a região aurífera. ${ }^{33}$

\footnotetext{
Cf. Novinsky, Inquisição - Inventários, p. 73-74.

Ibid., p. 74

Ibid., p. 74 e. 221

31 Cf. IAN/TT, Inquisição de Lisboa, Processo de Inácio Cardoso de Azevedo, n. 11.784 .

32 Cf. Novinsky, Inventários, p. 127-129, 233.

33 Cf. IAN/TT, Inquisição de Lisboa, Processo de Sebastião de Lucena Montarroio, n. 5.478 (transcrição gentilmente cedida por Lina Gorenstein Ferreira da Silva).
} 
Mesmo o padre letrado, o sacerdote João Peres Caldeira, que, antes de ser preso, viaja para o Algarve - possivelmente temendo a chegada do Santo Ofício no Rio de Janeiro -, declarou que havia vendido sua chácara e seu barco de pesca e investido os recursos em moedas de ouro, "por não usar de suas letras e também na despesa da viagem". Aproveitou para entregar encomendas em Portugal, "tudo mandado pelo bispo do Rio de Janeiro", a saber, "embrulhos de ouro" e algumas barras. Além de homens de negócio, entre os receptores das mercadorias estavam um Padre Geral e um Desembargador. ${ }^{34}$

Médicos e advogados mais favorecidos pela sorte emprestavam a juros. ${ }^{35} \mathrm{Na}$ Bahia, encontramos o abastado médico Manoel Mendes Monforte envolvido em negócios diversificados, dentre os quais empréstimos a gente da nobreza da terra. Dentre outros, emprestou 5.000 cruzados a razão de juros de seis e quatro por cento ao Sargento-mor Domingos Ramos da Cunha, três mil cruzados ao Sargento Mor da Artilharia Inácio Teixeira Rangel, dois mil cruzados à viúva de um juiz dos órfãos da Bahia, quatro mil cruzados a um certo Diogo Pereira da Silva e 400 mil réis a um outro médico chamado João Alves de Vasconcelos, também morador da Bahia. ${ }^{36}$

\section{Considerações finais}

Embora a Universidade de Coimbra gozasse de relativa autonomia, ao menos, até as reformas pombalinas, a formação universitária de cristãos-novos e cristãos-velhos servia como elemento constitutivo das matrizes políticas, educacionais e pedagógicas alicerçadas pela Monarquia Católica. Se parte dos cristãos-novos formados não servira diretamente como oficiais de ambas as instituições, disponibilizaram sua mão-de-obra no mercado de serviços.

Não se deve esquecer que, assim procedendo, reproduziam as matrizes teóricas e práticas oficiais, visto que suas formações estiveram sob a tutela de tais aparatos de poder. Torna-se importante chamar a atenção para dois aspectos deste controle:

Cf. Novinsky, Inquisição, Inventários, p. 142-143.

Ibid., p. 118.

36 Ibid., p. 198-206. Infelizmente não encontramos no Rio de Janeiro nada similar ao caso deste médico. É o inventário mais longo compilado por Anita Novinsky. Para ilustrar, vale mencionar que este médico esteve envolvido até mesmo com "negócios" matrimoniais. Mantinha contatos com os irmãos Rodrigo e Manoel de Sande que negociavam com a Cúria Romana as dispensas de casamentos proibidos, tais como os considerados incestuosos de primos ou de tios e sobrinhas. 
1. suas atividades tinham como matrizes os elementos da disciplina e da pedagogia coimbrã e, no exercício prático de seus ofícios, respondiam às demandas ou querelas dos segmentos das elites coloniais (dentre os quais, os seus próprios interesses);

2. há ainda a ingerência de elementos constitutivos do poder simbólico conferido pelo porte do diploma universitário, o que se tornou um elemento crucial na reprodução do controle exercido pelo saber oficial sobre os seus concorrentes. Talvez, mais do que a existência dos aparatos de controle sofisticados, como o Desembargo do Paço, a Fisicatura-Mor, ou mesmo a Inquisição, a introspecção do paradigma oficial entre determinados segmentos da sociedade se daria pela persuasão, conferida por um certo ethos aristocrático, então vigente, e que instigava as viagens de estudos como meio de nobiliarquização alternativa.

Este controle secular e religioso sobre o ensino legitimava as práticas dos médicos e dos advogados perante os grupos que representavam. Em outras palavras, mesmo que o acadêmico não se inserisse nas administrações locais, régias ou eclesiásticas ao exercer suas funções no mercado de serviços reproduzia os arcabouços teóricos da pedagogia conimbricense, tanto na área do Direito quanto na da Medicina.

No que diz respeito ao prestígio adquirido, além do grau de riqueza, raça e cor da pele - elementos importantes para os critérios seletivos na hierarquia e no repertório das sociabilidades que se configuravam nos trópicos - o capital cultural servia como elemento de assimilação e integração que, no período anterior à empreitada inquisitorial na cidade, em determinadas circunstâncias, se sobrepunha à "qualidade de sangue" e abria as portas da alta sociedade colonial aos descendentes dos conversos. O título universitário, na prática, acabava representando um processo social mais amplo de desvincular os cristãos-novos de seus grupos de origem e assimilá-los na sociedade enquanto letrados, isto é, de deslocar as lealdades da esfera de sua realidade imediata para a de um poder abstrato, corporificado nas identidades de ofício. De cristãos-novos a advogados; de cristãos-novos a médicos.

Ao acompanhar a trajetória de um grupo de acadêmicos cristãos-novos, tentando juntar os fios de uma tradição sempre evocada por setores da historiografia, que lhes conferia o status de uma protoburguesia citadina, deparamo-nos com setores cujo projeto era o de se "aristocratizarem", tornarem-se senhores de homens e terras nos moldes da plantation escravista. 
Ao procurar agnósticos, cépticos ou mesmo elaboradores de complexas cosmologias (para citar os mais conhecidos, Henequim, Bartolomeu de Gusmão ou Menóquio), deparamo-nos com homens preocupados exteriormente em se ajustar à sociedade em que viviam. Médicos, advogados e sacerdotes que compartilhavam as insígnias da sociedade colonial, no exercício cotidiano de seus ofícios e difundiam os princípios da cultura oficial da pedagogia conimbricense.

Por outro lado, as "vozes" que nos chegam através da documentação inquisitorial nos informam do empenho de alguns em produzirem uma retórica diante dos funcionários do Santo Ofício, ao iniciarem confissões. O cenário, então, é outro. O discurso passa a ser subversivo...

A maior parte destes letrados, formados em Direito Canônico, ao invés de elaborarem complexas discussões teológicas, criaram métodos práticos para solucionar os seus problemas, buscando, assim, dar continuidade às suas vidas e retomar suas liberdades, mesmo que empobrecidos.

Em suma, os cristãos-novos letrados do Rio de Janeiro foram elementos cruciais nos critérios de dominação utilizados pela Monarquia Católica: foram formados e agiram como seus serviçais para atuar nos trópicos. No entanto, em princípios do século XVIII, a Inquisição atuou na cidade, levando para os cárceres lisboetas parte significativa dos letrados luso-brasileiros, fluminenses, de origem judaica.

Os letrados do Rio de Janeiro foram acusados de profanações heréticas, mais precisamente, do crime de judaísmo e é então que se desarticulam seus projetos assimilativos e integracionistas, perdem engenhos, bens, haveres e honras. Parte das "famílias principais da terra" é exilada. 